\title{
GHOST \\ A Satellite Mission Concept for Persistent Monitoring of Stratospheric Gravity Waves Induced by Severe Storms
}

\author{
David M. Tratt, John A. Hackwell, Bonnie L. Valant-Spaight, Richard L. Walterscheid, \\ Lynette J. Gelinas, James H. Hecht, Charles M. Swenson, Caleb P. Lampen, \\ M. Joan Alexander, Lars Hoffmann, David S. Nolan, Steven D. Miller, \\ Jeffrey L. Hall, Robert Atlas, Frank D. Marks Jr., and Philip T. Partain
}

GHOST would continuously monitor storm-induced gravity waves, observing their development through complete storm life cycles in order to elucidate causal relationships between storm phenomena linked to latent heating and gravity wave production.

W e introduce a new mission concept, the Geostationary Hosted Observatory for Storm Tracking (GHOST), to investigate stratospheric gravity wave $(\mathrm{GW})$ signatures and their relationship to the severe weather events that generate them. GHOST would develop an improved scientific understanding of the production characteristics of atmospheric GWs by severe storms that develop over land and oceans. A key observable is the temporal evolution of GW patterns as severe weather events build or decay. This currently inaccessible knowledge is critical to informing future diagnostic techniques for continuously judging storm development and intensification by enabling an entirely new predictive sensor that could be incorporated into future operational weather satellite constellations.

When Hurricane Katrina struck the Gulf Coast of the United States in 2005, it provided a stark example of the vulnerability of human society to natural disasters and the importance of observations and warning systems. Katrina, which resulted in the deaths of more than 2,000 people and is estimated to have caused
AfFiliations: Tratt, HackWell, Valant-Spaight, Walterscheid, Gelinas, Hecht, Lampen, and Hall-The Aerospace Corporation, Los Angeles, California; SWENson-The Aerospace Corporation, Los Angeles, California, and Department of Electrical and Computer Engineering, Utah State University, Logan, Utah; AleXANDERCoRA Office, NorthWest Research Associates, Boulder, Colorado; HOFFMANN - Jülich Supercomputing Center, Forschungszentrum Jülich, Jülich, Germany; NoLAN-Department of Atmospheric Sciences, Rosenstiel School of Marine and Atmospheric Science, University of Miami, Miami, Florida; Miller ANd Partain-Cooperative Institute for Research in the Atmosphere, Colorado State
University, Fort Collins, Colorado; ATLAS and MARKS-NOAA/Atlantic Oceanographic and Meteorological Laboratory, Miami, Florida CORRESPONDING AUTHOR: David M. Tratt, dtratt@aero.org

The abstract for this article can be found in this issue, following the table of contents.

DOI:I0.II75/BAMS-D-17-0064.I

In final form 5 March 2018

(O)2018 American Meteorological Society

For information regarding reuse of this content and general copyright information, consult the AMS Copyright Policy. 
some $\$ 125$ billion in damage, was one of the worst disasters in U.S. history. Although forecasts 3 days in advance using dynamical models proved highly accurate for the storm track, the forecasts of the storm intensity and the related magnitude and location of the storm surge were less so and indicate the need for enhanced research and new types of observations (National Science Board 2007). The standard definition of tropical cyclone (TC) rapid intensification (RI) is $30 \mathrm{kt}\left(1 \mathrm{kt}=0.51 \mathrm{~m} \mathrm{~s}^{-1}\right)$ of surface wind speed increase within $24 \mathrm{~h}$, which is slightly less than the 95th percentile of 24-h increases. The National Hurricane Center (NHC) has maintained an operational TC-RI forecast capability since the early 2000s, and improved versions are currently undergoing trials at the NHC's Joint Hurricane Testbed. However, notwithstanding recent progress in the ability to predict RI (Kaplan et al. 2015), this remains a difficult forecast problem (DeMaria et al. 2014; Emanuel 2017; Rogers et al. 2017) that is hindered by a lack of knowledge concerning the processes occurring below the central dense overcast region of the storm (Willoughby et al. 1982; Rappaport et al. 2009).

GWs are waves in a fluid medium where the restoring force is buoyancy; they are the ubiquitous consequence of powerful disturbances in the atmosphere and are caused by thunderstorms, TCs, and other extreme events. The relation between GWs and storms is illustrated by the snapshot in Fig. 1 of waves radiated by cyclonic storm systems as observed in a carbon dioxide $\left(\mathrm{CO}_{2}\right)$ spectral band by the Atmospheric Infrared Sounder (AIRS). The retrieved brightness temperature (BT) excursions of the GW signal in this figure are of similar order to the noiseequivalent differential temperature (NEDT) of AIRS, so the derived images exhibit a pronounced granular appearance.

Much is known about the propagation of GWs in the atmosphere, including their dispersion relations and the effects of background winds, and computer models have recently been developed and tested that connect GWs to the convective latent heating generated within storms (Stephan and Alexander 2015). Using AIRS observations over the period 2002-16 and TC intensity estimates provided by the International Best Track Archive for Climate Stewardship (Knapp et al. 2010), Hoffmann et al. (2018) find a statistically robust correlation between stratospheric GW activity and TC intensification, lending support to the idea that variability in GW signatures as a result of changing storm behavior may constitute a reliable diagnostic tool for RI. However, this putative relationship has yet to be fully tested considering the coarse time sampling of current GW observations. What is lacking at present are continuous views of GWs around severe weather systems with a temporal cadence sufficient to determine the frequency and phase velocity of the emanating waves. Such observations can be provided by an appropriate camera on a geostationary Earth-orbiting (GEO) satellite. With these data and the wealth of existing weather observations and storm models, it would be possible to test the hypothesis that GW signatures around severe weather events are directly linked to the time history of a storm's intensity (Nolan and Zhang 2017).

Continuous observations of GWs need to be made in the stratosphere because this atmospheric region is both close to the tropospheric storm source and provides views of the waves that are unobstructed by clouds. A portion of the storm-generated wave spectrum reaches the stratosphere quickly. These are the fast-moving GWs that have both large vertical wavelengths and high frequencies. The spectrum of GWs generated by latent heating varies with the vertical profile of the heating (Nicholls et al. 1991) as well as the horizontal spatial scales and temporal variation (Holton et al. 2002; Alexander and Holton 2004). Numerical simulations have shown that the relationship of heating depth $D$ to vertical wavelength $L_{z}$ tends to produce a peak in the spectrum at $L_{z}=2 D$, that is, $20 \mathrm{~km}$ (Holton et al. 2002; Pfister et al. 1993; Beres et al. 2004). The horizontal wavelengths $L_{h}$ reflect the scale of the forcing. For individual cells this means the dominant wavelengths are $\sim 20 \mathrm{~km}$, with those shorter than $\sim 10 \mathrm{~km}$ being evanescent. For GWs with $L_{z}$ and $L_{h} \sim 20 \mathrm{~km}$, the vertical group velocity is $\sim 30 \mathrm{~m} \mathrm{~s}^{-1}$. The waves are excited in the middle troposphere; hence, under suitable background wind and stability conditions, the wave patterns reach upper-stratospheric altitudes in $\sim 20$ minutes. Thus, changes in the underlying storm intensity could be diagnosed in the stratosphere on time scales relevant to forecasting needs. GW observations in the visible channels from GEO satellites, such as the Geostationary Operational Environmental Satellite (GOES), are frequently obstructed by clouds within tropospheric storm systems. Stratospheric observations, which are essentially above these obscuring clouds, are available from low-Earth-orbiting (LEO) spacecraft-for example, AIRS and the Infrared Atmospheric Sounding Interferometer (Hoffmann et al. 2014) - but these cannot image at the needed cadence because of their orbits (taking snapshots twice daily, whereas GHOST would acquire movies).

The GHOST concept assumes an infrared imager on a geostationary satellite to observe stratospheric 
GWs in the $4.3-\mu \mathrm{m} \mathrm{CO}_{2}$ wave band over an area extending from the equator to near $45^{\circ} \mathrm{N}$ and from the Atlantic west of Africa to the vicinity of the Continental Divide. A second channel at $4.4 \mu \mathrm{m}$ would allow monitoring of deep convective clouds simultaneously with the GWs. From this vantage point, the imager would observe GWs emanating from severe weather events over both ocean and land to perform a comprehensive study of the relationship between storm development and GW spawning. The GHOST program would proceed in two phases, consisting of an initial scientific study followed by a real-time demonstration. With its utility proven, future operational GEO weather platforms or other GEO constellations, such as communications satellites, could incorporate sensors with analogous functionality to monitor storm activity over all ocean basins globally, with the data being downlinked in near-real time for timely processing to enhance forecasting accuracy.

\section{SCIENCE BACK-} GROUND. Atmospheric convection over continental landmasses plays a critical role in the Earth's climate system (Jensen et al. 2016). Convective processes redistribute energy and momentum from the troposphere to the stratosphere and above. Convection over land also occurs where radar coverage is essentially complete,
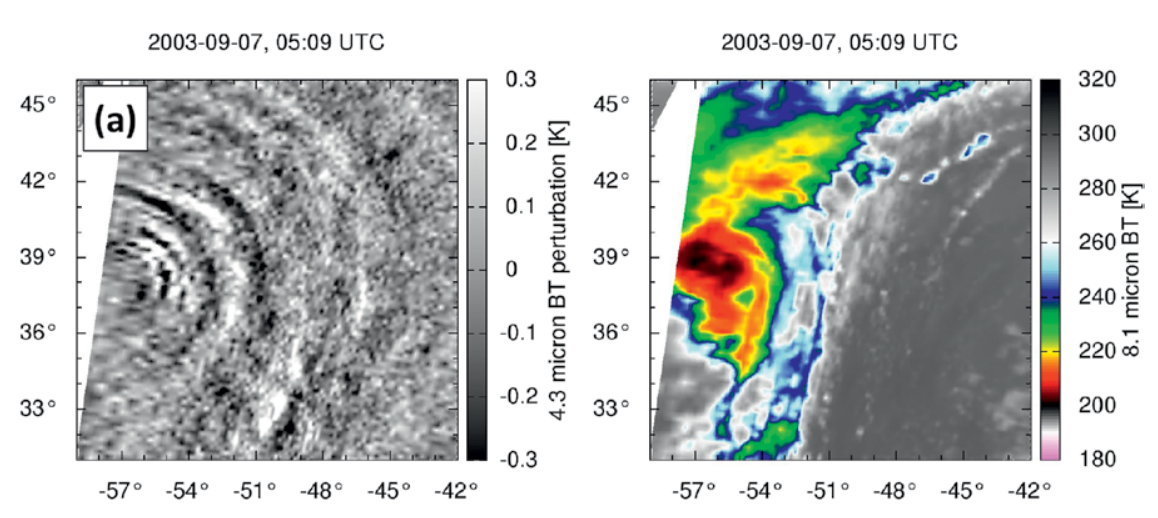

2005-08-26, 18:41 UTC
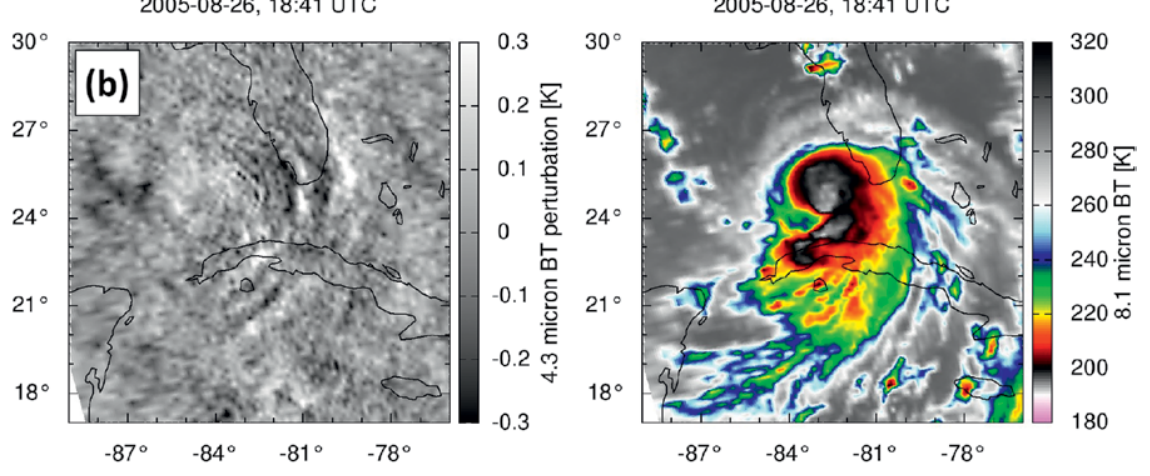

2008-11-08, 07:43 UTC
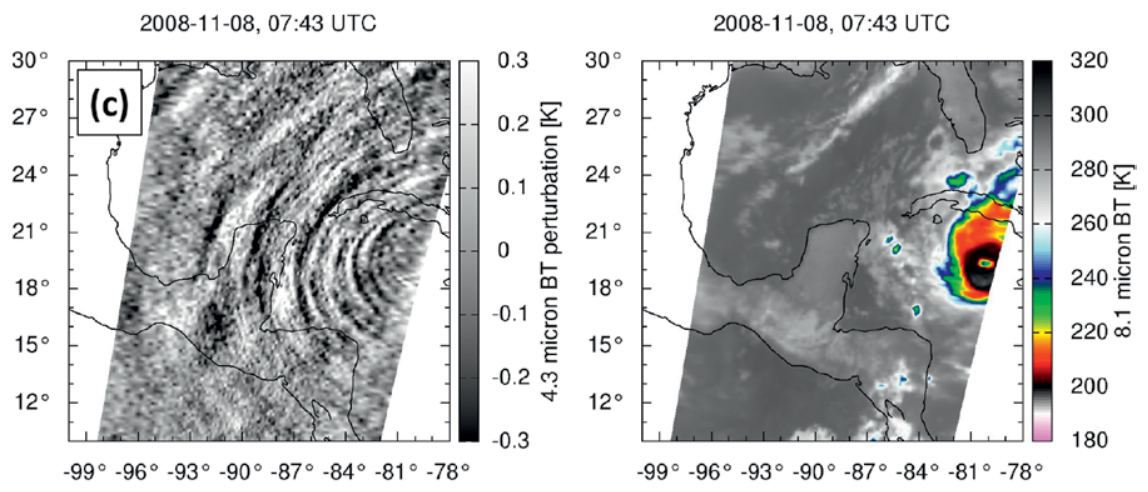

2012-10-29, 18:19 UTC
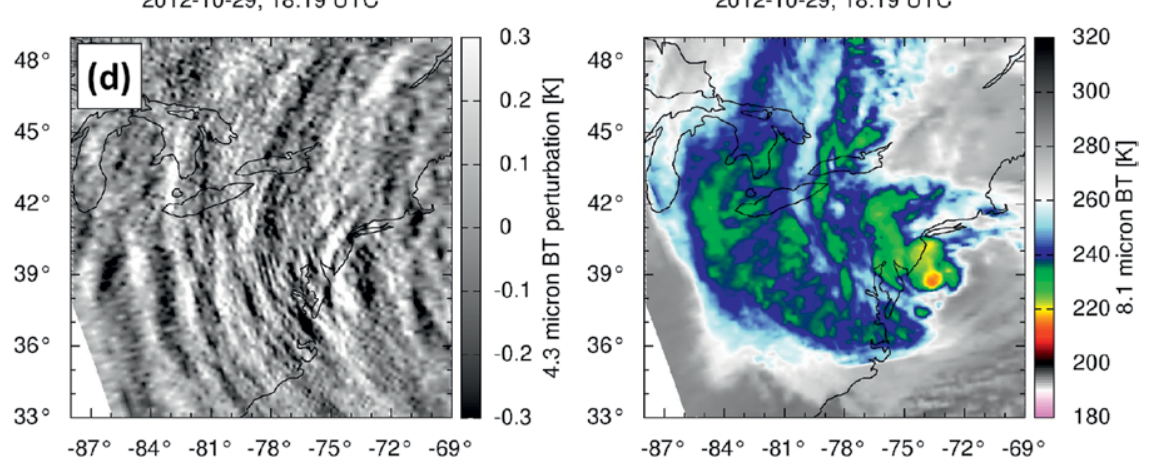

FIG. I. AIRS observations of (left) stratospheric GWs in 4.3- $\mu \mathrm{m}$ BT perturbation and (right) cloud observations in 8.1- $\mu \mathrm{m}$ BT of four hurricanes: (a) Hurricane Fabian (2003), (b) Hurricane Katrina (2005), (c) Hurricane Paloma (2008), and (d) Hurricane Sandy (2012). 


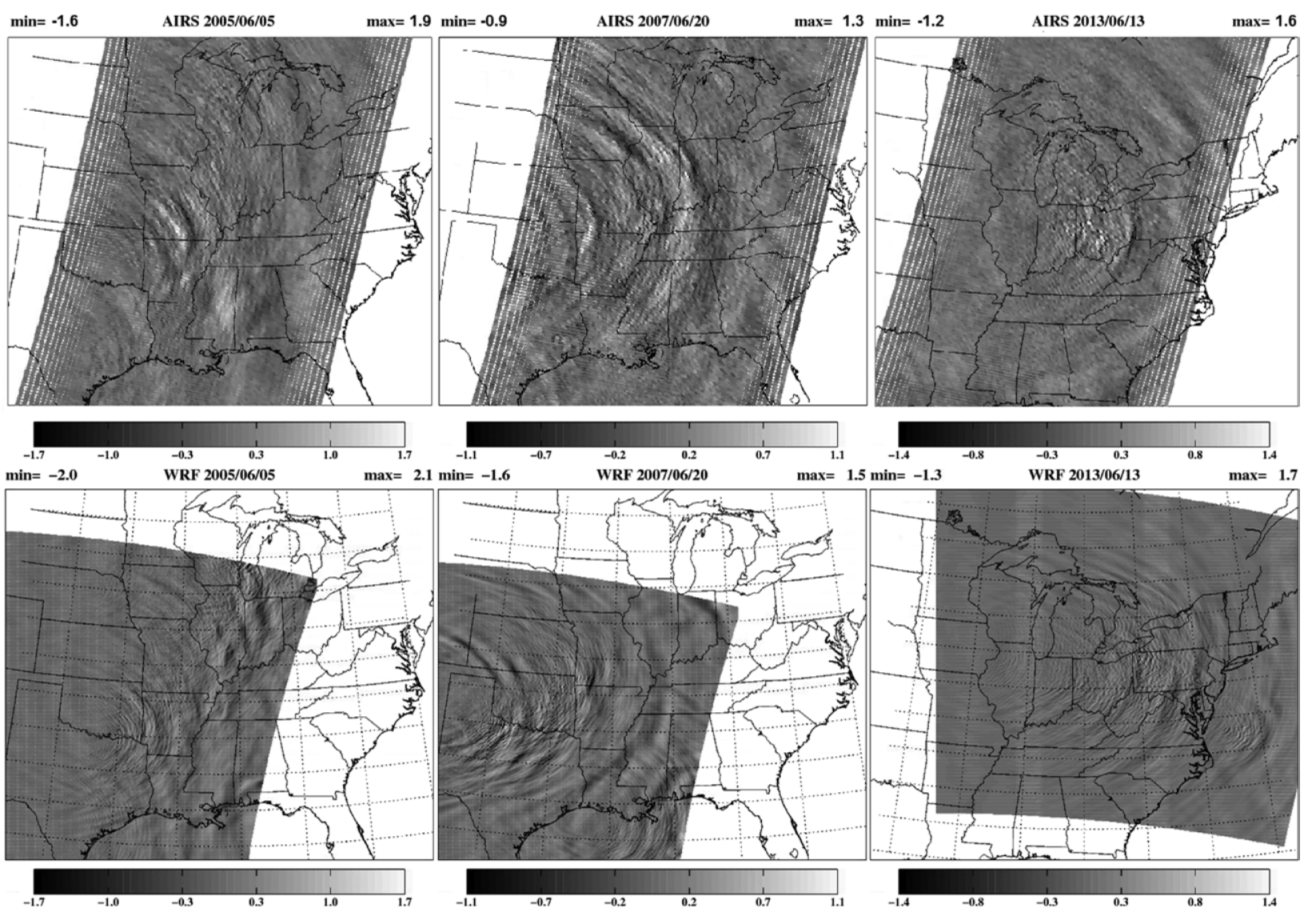

FIG. 2. The observed response for three types of convective systems and the corresponding simulated responses. (top) AIRS BT anomalies for (left to right) a squall line case, a mesoscale convective complex, a mesoscale convective system. (bottom) As in (top), but showing images computed from the idealized model driven with a radar precipitation-derived heating. Shading denotes BT anomalies $(K)$ contemporaneous with the satellite measurements. (Stephan and Alexander 2015).

and this region can serve as a laboratory for understanding the GW signatures seen in terms of the variations in latent heat release throughout the life cycle of storms. Convective latent heat release is a major source of energy for driving storms as well as producing GWs. Deep convection is a known prolific generator of GWs (Walterscheid et al. 2001; Grimsdell et al. 2010; Hoffmann and Alexander 2010; Walterscheid and Christensen 2016). In this regard, the North American Great Plains have been identified as a global "hot spot" of convective GW activity (Hoffmann and Alexander 2010; Hoffmann et al. 2013; de Groot-Hedlin et al. 2017) and thus constitute an ideal, geographically constrained natural laboratory for the GHOST study.

While studies of wave generation by latent heat sources have a lengthy history (e.g., Holton 1972), the majority of these were linear model studies or qualitative comparisons. Attempts at quantitative validation of such models with observations are plagued by a variety of complicating factors, including the difficulty for cloud-resolving models to obtain the correct timing and location of rain cells, which prevents direct validation of GWs observed in the vicinity of a precipitating storm. Latent heating is a strong forcing, and nonlinearity is very important in determining wave amplitudes. In addition, evaporation, ice processes, and horizontal transport of hydrometeors (from where they form to where they fall) are other important factors in relating precipitation to latent heating (Shige et al. 2004; Stephan and Alexander 2015).

GWs, while relatively small in scale, are collectively a significant component of the atmospheric momentum budget and are therefore an important consideration in climate modeling. This is true particularly at upper levels in the atmosphere because as GWs propagate vertically and horizontally away from sources, the growth in amplitude is inversely proportional to the square root of the exponentially decreasing atmospheric density. Eventually, they will break (or otherwise dissipate) at a remote distance 
or altitude from the source, and this imparts a momentum force on the larger-scale circulation (Fritts and Alexander 2003, and references therein). This so-called GW drag is a controlling force at altitudes near the mesopause, and GW drag near the tropopause and in the stratosphere, while secondary to Rossby wave drag, is still important for alleviating wind biases that impact weather forecasting and climate simulations (Alexander et al. 2010). The strength of the drag force is proportional to the divergence of the pseudomomentum flux carried by the waves, which is therefore key to understanding wave effects on the circulation. While generally difficult to measure directly from satellites, it can be directly derived from GHOST data combined with supplementary large-scale wind data obtained from reanalysis products.

Recent studies (Stephan and Alexander 2015; Stephan et al. 2016) have moved the field from qualitative to quantitative determination of the relationships between precipitation, latent heating, and GWs. The approach uses the dense network of scanning precipitation radar across the continental United States (CONUS), an algorithm relating rain rate and echotop height to instantaneous latent heating profiles, and an idealized dry dynamical model forced by the derived latent heating. In developing the algorithm, an ensemble of cloud-resolving model runs was used to evaluate the sensitivity to model choices, most importantly the microphysics scheme. Because the forcing for the idealized model in this approach is observed precipitation, waves in the model can be directly validated by instantaneous measurements from satellites passing overhead or ground-based sensor network measurements. Examples showing the idealized model waves and comparing near-instantaneous measurements from satellite are shown in Fig. 2, in which the range of the brightness temperature anomalies associated with the GWs in each case is a close match between the modeled and observed GW amplitudes. The modeled and observed horizontal wavelengths of the GWs also agree in general, although the details differ as a result of the use of an idealized model. These results demonstrate that an idealized Weather Research and Forecasting (WRF) Model can accurately replicate the spatial patterns and amplitudes of observed GWs.

Given the success of these snapshot studies of storms and GWs, it is now an appropriate time to take the next step. This entails studying the temporal evolution of the storms and developing relationships between the GW signatures and the temporal evolution of the storms as they grow, intensify, and decay.
The signature of GWs, in terms of wavelength and period, emitted from a TC is expected to vary considerably as the storm develops and intensifies. TCs are powered by latent heat release, largely by deep convection in the eyewall, and by gradient adjustment processes associated with rapidly rotating asymmetries in the eyewall of the storm (Chow et al. 2002; Schecter 2008; Hendricks et al. 2010). Although the entire TC life cycle is of interest to forecasters, there is one important factor in particular (RI) that can best be resolved through persistent observations such as those possible from the GEO vantage point. RI is of enormous importance, not only because of the immediate risks presented, but because it is a necessary stage of development for the large majority of storms that reach "major" hurricane intensity (Lee et al. 2016). In many cases, the onset of towering convection either precedes RI by $6-12 \mathrm{~h}$ or is coincident with it (Kelley et al. 2004; Guimond et al. 2010; Rogers et al. 2013). These differences appear to be related to the persistence of convection as well as its location relative to the radius of maximum winds and the inertial stability of the core. Each of these properties-the duration of the convective burst and the inertial stability of the surrounding flow-will modify the properties of the GWs that are emitted.

To illustrate the GWs generated by TCs, Fig. 3 shows temperature anomalies in the stratosphere produced by the WRF Model using the idealized modeling framework developed by Nolan (2011) to simulate TCs in controlled environments. These simulations have approximately constant wind shear (in log pressure height) from 850 to $20 \mathrm{hPa}$ and are intended to compare GWs produced by TCs of different intensity. The zonal wind varies from -5 to $+15 \mathrm{~m} \mathrm{~s}^{-1}$ between these levels. Although the GWs are attaining $30-\mathrm{km}$ altitude, the effects of the westerly flow in the stratosphere are evident from the east-west asymmetry of the wave structures.

One simulation uses a fixed sea surface temperature (SST) of $27^{\circ} \mathrm{C}$ and produces a TC that slowly intensifies to category 2 strength, while the other uses an SST of $29^{\circ} \mathrm{C}$ and produces a TC that rapidly intensifies to category 4 strength. Both simulations use a large outer domain with $18-\mathrm{km}$ grid spacing and nested, vortex-following grids with 6 - and $2-\mathrm{km}$ grid spacing, with 80 vertical levels between the surface and altitude above the ocean surface $z=40 \mathrm{~km}$. It is clear from the figures that each TC is producing GWs that reach the upper stratosphere and radiate outward in concentric circles. The wave-filtering effect caused by intermediate winds seen in previous studies (Kuester et al. 2008; Hecht et al. 2009; Stephan and Alexander 2015; see also Fig. 2) is evident, with the 

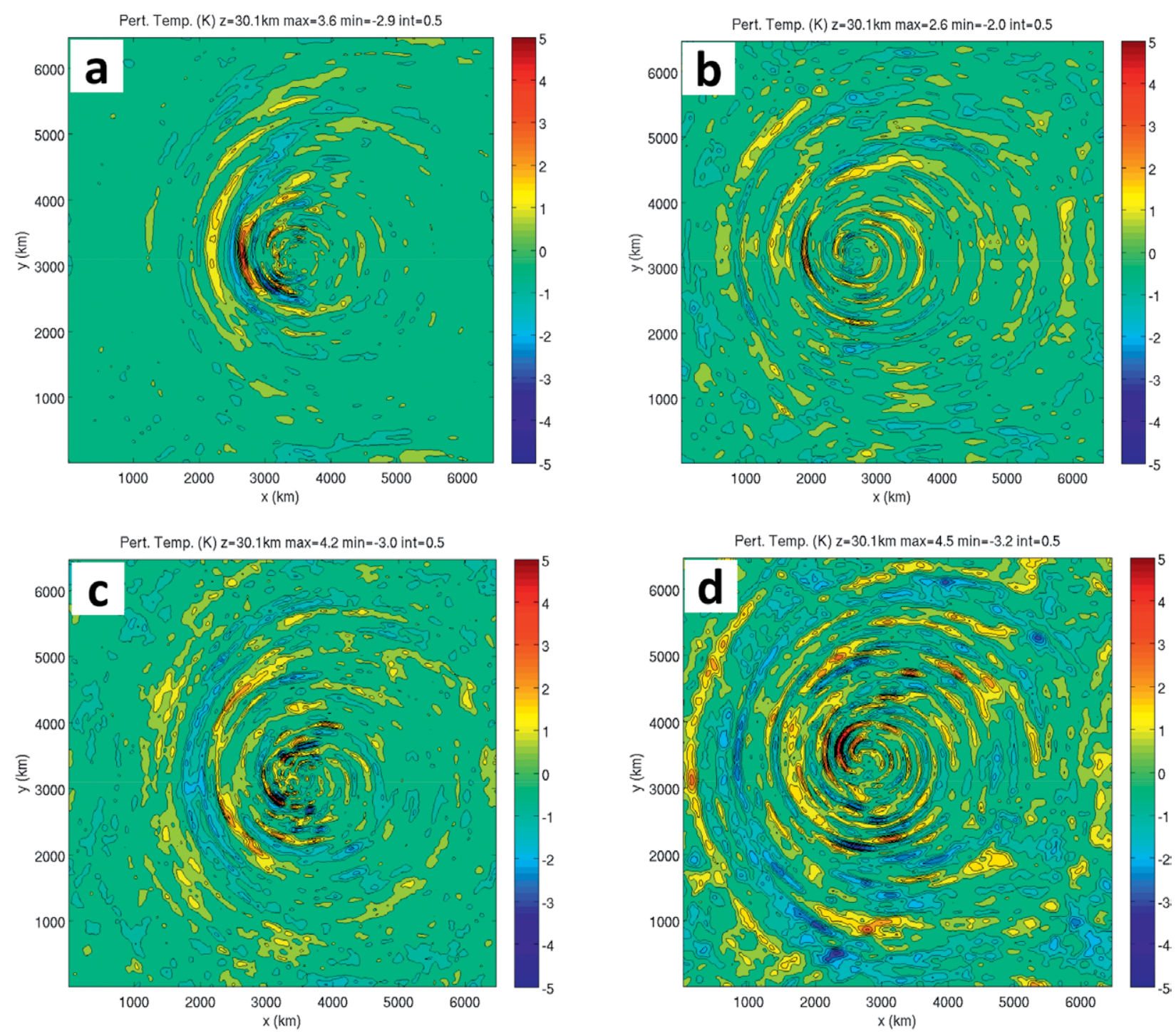

FIG. 3. GWs in the stratosphere radiating from TCs in idealized simulations using the WRF Model, for intensifying cyclones with different intensity. Each plot shows temperature anomalies at 30-km altitude (i.e., beneath the damping layer, which lies between $32 \mathrm{~km}$ and the model top near $40 \mathrm{~km}$ ) for (a) a TC with SST = $27^{\circ} \mathrm{C}$ at time $t=3$ days; (b) as in (a), but at $t=5$ days; (c) a TC with SST $=29^{\circ} \mathrm{C}$ at $t=3$ days; (d) as in (c), but at $t=5$ days. The plots show the entirety of the outer domain with $18-\mathbf{k m}$ grid spacing.

temperature anomalies suppressed on the east side of the storm and the wave fronts compacted more closely on the west side. As the stronger storm exceeds major hurricane strength, the amplitudes become larger and the waves become more clearly organized and appear to be overcoming the filtering effect. Thus, models can illustrate changes in the amplitude and structure of the stratospheric GW field emanated by TCs as they develop.

GHOST science objectives. GHOST was conceived to examine how stratospheric GW properties relate to their tropospheric sources, and how that knowledge can be utilized to understand storm dynamics and intensification. To answer this question, it will be necessary to a) determine the relationship between the evolution of convective storms over land and changes in the signatures of GWs propagating in the stratosphere and $b$ ) determine the signatures of GWs produced by TCs over their growth and decay life cycle.

These distinct yet related objectives recognize the need to observe two broadly different kinds of weather systems-those over land and those over the ocean-in order to provide an informed answer to the overarching science question. They also help in organizing the investigation requirements because of the distinct differences required in the methodology as 
a result of the differences in the availability of storm data over ocean versus land.

In addition to these storm-focused objectives, GHOST data would contribute to improved global weather forecasting and climate prediction models. GW drag is an important component of the momentum budget in the stratosphere and mesosphere. To approximate the drag from small-scale unresolved GWs, global models parameterize this force. Momentum flux and detailed wave properties (e.g., phase speed and horizontal wavelength) are specified at a "source level" in the lower atmosphere. Wave breaking or dissipation is estimated as a function of height, and the resulting drag force is added as a forcing term to the momentum equation. However, too little is known about the detailed sources, wave momentum fluxes, and wave properties to accurately estimate the wave drag, so GW parameterizations are tuned to reduce model wind biases and to obtain realistic general circulation. While it is generally difficult to measure GW momentum flux directly from satellites, it can be directly derived from GHOST data with only supplementary large-scale wind data obtained from reanalysis products.

GHOST staring from GEO will provide the wave frequency, which is generally nonzero for waves generated by convection and frontal systems. Along with direct imaging of the wave horizontal wavelengths and propagation directions, such measurements will permit calculation of the vertical wavelength, and hence conversion of brightness temperature to sensible temperature, and enable estimation of the wave momentum flux (Alexander et al. 2009).

Investigation approach. To characterize waves in the stratosphere and their sources, two sensor channels are required: one to observe GW-induced perturbations in the temperature of the stratosphere $(4.26 \mu \mathrm{m})$ and one to image clouds that are present in the upper troposphere $(4.40 \mu \mathrm{m})$. The purpose of the cloud channel is to assess the local and time-dependent cloud-top height and temperature; it is used to identify GW sources and as a proxy for storm intensity when data from radars are not available. It will also indicate whether clouds may be contaminating the stratospheric signal in the rare instances when they may attain altitudes approaching $20 \mathrm{~km}$.

Basing the functional requirements on current scientific understanding of GW phenomena, the requirements for observational cadence, sensitivity, and horizontal resolution are derived from model simulations, specifically the amplitude and spatial spectrum of simulated GWs. The AIRS mission has demonstrated successful detection of GWs in the stratosphere, but the imaging capabilities of the AIRS sensor $(60-\mathrm{mK}$ NEDT at $250 \mathrm{~K}$ for the $4.26-\mu \mathrm{m}$ region and $13.5-\mathrm{km}$ spatial resolution) (Hoffmann et al. 2014) are only minimally sufficient to meet the science needs of the GHOST mission (as is evident from the noisy character of the GW retrievals portrayed in Fig. 1), even if provided at a faster cadence.

The requirements on imaging cadence of the GW channel are based on resolving the frequency content of the target waveforms. The interval between images must be short enough to avoid undue temporal aliasing of the waveform and ideally allow for oversampling. The first wave to arrive in the stratosphere from a tropospheric source has a period on the order of the buoyancy period ( $\sim \mathrm{min})$, requiring an imaging cadence of $<1 \mathrm{~min}$. The cadence of the cloud channel is required to be $<10 \mathrm{~min}$ based on the evolution characteristics of towering clouds within storms as they build and decay. Both the observed and modeled GW amplitudes from convective sources are typically $\sim 0.5-5 \mathrm{~K}$ in the stratosphere, which, to be able to clearly distinguish wave signatures, translates radiometrically into a scene brightness sensitivity requirement of $<40 \mathrm{mK}$ at $250 \mathrm{~K}$. Our performance calculations for the GHOST sensor, assuming conservative values for optical transmittance, detector quantum efficiency, and detector red noise, predict an NEDT of $\sim 6 \mathrm{mK}$ at $250 \mathrm{~K}$ after summing image frames for $30 \mathrm{~s}$.

Rapid and localized changes in latent heating generate the broadest spectrum of waves. Largerscale, slower-evolving heating generates only the wave scales larger than those of the heating but are generally seen at later times because of slower vertical propagation. An observation of the entire spectrum of GWs produced is not needed to explore the relationship between evolving storm strength and their GW signatures. We require only observations of GWs with horizontal wavelengths $\geq 20 \mathrm{~km}$ to avoid significant truncation of the GW spectrum, implying a $\leq 10-\mathrm{km}$ spatial-resolution requirement for the imager.

The primary indicator to be used for characterization of storm intensity is latent heat, and the proxy for determining latent heat is rain rate. Observations of rain rate for storms over CONUS are provided by the existing network of Next Generation Weather Radar (NEXRAD) stations. Adequate radar coverage to observe rain rates over various stages of storm development requires observations over a period of at least $6 \mathrm{~h}$ per storm for a minimum of 30 storms ( 20\% statistics). Recent studies (Stephan and Alexander 2014, 2015) used the Storm Total Rainfall 
Accumulation product (OFCM 2006) for individual NEXRAD stations providing radar-estimated rainfall storm accumulations, $\sim 1 \mathrm{~mm}(10 \mathrm{~min})^{-1}$ resolution within $230 \mathrm{~km}$ of the radar in polar coordinates with a spatial resolution of $2 \mathrm{~km}$ radially and $1^{\circ}$ azimuthally. This was sufficient to observe the scales of individual convective elements that are important to stratospheric GW generation. With these resolutions and an algorithm to convert rain rate to latent heat deposition, these studies produced simulated responses to convective systems over the United States that agreed well with GWs observed both in AIRS images and in a dense array of surface pressure sensors (Stephan et al. 2016). To do this it was necessary to perform suites of WRF simulations to develop (train) the algorithms (Stephan and Alexander 2015). The GHOST mission would follow this same approach to characterize storm intensity and to observe its evolution.

One of the difficulties in studying storms over the ocean is obtaining the necessary correlative data on growth and decay to support the study. To address these issues, we have developed the following two approaches: 1) study TCs near land where radar or aircraft can view them and 2) develop proxies for storm strength when they are out of radar range using the cloud observations. In addition to the land-based radar, the NOAA Hurricane Research Division collects radar datasets on most TCs they penetrate. Data collected by the NOAA P3 aircraft sensors, which measure precipitation and winds from 0.5 - to $18-\mathrm{km}$ altitude at $150-\mathrm{m}$ range resolution in hurricanes within the Caribbean, Gulf of Mexico, and off the U.S. Atlantic coast, would meet the requirements on rain-rate observations (e.g., Houze et al. 2006).

The requirements for the detection of GWs in the stratosphere above a TC are the same as for storms over land. The storm characteristics will be determined through a combination of ancillary data, such as radar-derived rainfall rates and in situ winds and precipitation, with the cloud extent provided by the cloud channel (15-km altitude) of the GHOST imager. In this way the observed GW features will be correlated with latent heating in TCs, both near the eyewall and in the rainbands, as well as overall storm intensity given by central pressure, sustained winds, and storm size (radius) provided by NOAA products (http://wwwt.nco.ncep.noaa.gov). We require pressure, winds, and size to be more accurate than the typical differences between storms of different classifications (stages and categories). The precision of the available data ( $\sim 5 \mathrm{~m} \mathrm{~s}^{-1}$ winds, 4 -hPa pressure, and $\sim 10 \mathrm{~km}$ in size) (Landsea and Franklin 2013) are better than the difference between hurricane storm categories as defined by the Saffir-Simpson scale. These uncertainties are also typically $<10 \%$.

However, given the complexity of the wind field in the vicinity of the storm, the GW propagation characteristics in the stratosphere will be studied using correlative WRF simulations. The idealized modeling framework developed for WRF by Nolan (2011) allows the storm intensity and storm size to be controlled through initial and boundary conditions, and the large-scale temperature and wind profiles can also be varied independently. The model can thus be evaluated and improved by comparison to cloud imagery observations in the troposphere and GHOST GW observations in the stratosphere, providing insight into whether the upper-level adjustment processes are handled correctly and whether waves of the right wavelength and amplitude are reproduced by the model. Simulations can explore how the GW signatures in the lower stratosphere depend on storm intensity, intensification rate, and the surrounding environment. Real-case simulations can also be used to assess the effects of realistic interactions between tropical cyclones and the surrounding synoptic environment. The results of such studies can provide the context and guidance needed to understand the relationship between GWs observed by GHOST and the underlying TC dynamics.

These investigations include a significant amount of new research. Some aspects of this approach could be addressed with existing measurements and research funding prior to implementing GHOST, including 1) fundamental research on the relationships between precipitation, latent heating, and waves on short time scales (minutes to hours); 2) case study research focusing on rapidly intensifying storms and storms at tropical latitudes; 3) further research on GWs and latent heating in the complex wind environments encountered in cyclonic storms; and 4) case studies utilizing existing airborne radar measurements over open ocean.

Measurement traceability, data sources, and models. The flow of investigation requirements from science question to objectives, from geophysical parameter to instrument, model, and other data source requirements is shown in Table 1. Sufficient data to achieve the science objectives would be acquired over a baseline mission duration of 2 years.

GHOST MEASUREMENTS. GHOST is a two-channel infrared imager, staring from geostationary orbit, designed to detect stratospheric GWs at altitudes centered at $30-40 \mathrm{~km}$ and tropospheric clouds (see the 


\section{GHOST INSTRUMENT OVERVIEW}

HOST is a compact two-channel $\mathbf{U}_{\text {wide-field midwave infrared }}$ (MWIR) camera designed for deployment on a GEO platform. It features a straightforward staring design using large-area focal plane arrays (FPAs) that eliminates the need for operator involvement in pointing control, and consequently the risk of transmitting disturbances to the host platform, that would be associated with a scanned system using smaller FPAs.

Figure SBIa shows the optical concept: a robust two-detector camera. The camera uses only three powered lenses to image infrared radiation onto the two FPAs. A beamsplitter divides the radiation between the channels. Because the wavelengths of the two channels are close, a power splitter may be used instead of a dichroic splitter. Compact optics and the absence of mechanisms, except for a one-time door, leads to the simple and compact mechanical layout illustrated in Fig. SBIb. The GHOST payload accommodation requirements are commensurate with the limited resources typically allocated to hosted payloads (Table SBI).

Absolute radiometric calibration and pixel-to-pixel relative calibration ("flat field") are provided by a small infrared source (not shown in Fig. SBI) positioned at the cold stop immediately outside the entrance aperture perimeter. The source location at the pupil stop ensures uniform radiation at the FPAs for the purposes of flat fielding the data. The calibrator has a $<200-m s$ response time, uses little power, and requires no mechanisms.

The camera's $9.6^{\circ} \mathrm{FOV}$ is driven by the requirement to view from the midAtlantic coast to the Rocky Mountains and from the equator to $50^{\circ} \mathrm{N}$ latitude. The camera's focal length is driven by details of the FPA pixel count and pixel spacing. A $2048 \times 2048$ pixel FPA was selected because smaller arrays are unable to reliably resolve a $20-\mathrm{km}$ wave
TABLE SB I. GHOST platform accommodation requirements.

\begin{tabular}{|lc|}
\hline \multicolumn{1}{|c|}{ Parameter } & GHOST \\
\hline Size $(\mathrm{m})$ & $0.46 \times 0.5 \mathrm{I} \times 0.50$ \\
\hline Weight $(\mathrm{kg})$ & 33 \\
\hline Power $(\mathrm{W})$ & 94 \\
\hline Data rate $($ Mbps) & 6.5 \\
\hline
\end{tabular}

near the edge of the region of interest. GHOST's needs are met by off-the-shelf Teledyne Imaging Sensors Mercury Cadmium Telluride $(\mathrm{HgCdTe}) 2048 \times 2048$ H2RG FPAs with a 5.3- $\mu$ m cutoff, which were designed for the James Webb Space Telescope and have flown on multiple missions, including at least one at GEO (Levi and Agheli 201 I; Schueler 2012). Prior testing (Rauscher et al. 2014) has demonstrated that the H2RG detectors will exceed the needs of the GHOST mission. The estimated unit build cost of the GHOST payload is $\$ 10$ million for the self-contained instrument option. (a)

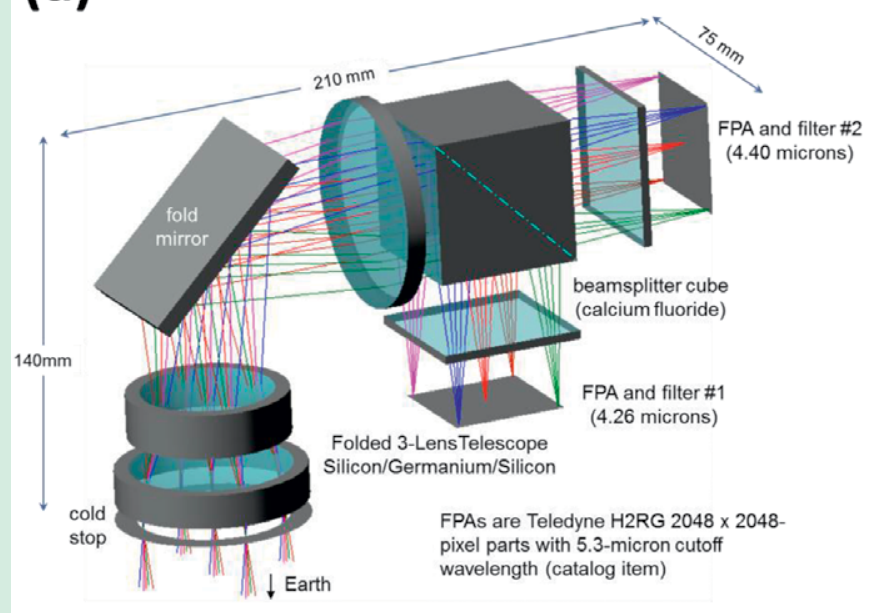

(b)

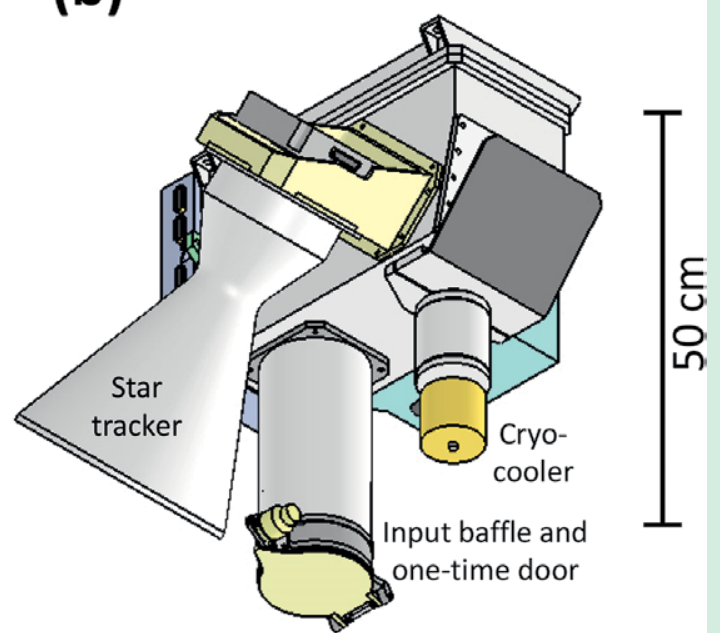

FIG. SBI. GHOST (a) sensor optical design and (b) mechanical layout.

sidebar for additional information). The stratospheric band is centered at $4.26 \mu \mathrm{m}$ [with a bandwidth (BW) of $60 \mathrm{~nm}$ ] and has a weighting function similar to the $4.3-\mu \mathrm{m}$-channel selection used for the analysis of AIRS observations. GHOST would continuously image GWs over their sources, so it will be situated such that it will observe GWs eastward from the Rocky Mountains to the mid-Atlantic coast over a latitude range of $0^{\circ}-50^{\circ} \mathrm{N}$. This capability allows determination of GW propagation parameters, which are unavailable from LEO satellite overpasses of storms, and detection of changes in the GW spectrum as a result of changes in the storms.

RAINFALL RADARS. Rainfall rates and echo-top heights required to determine latent heating in convective 


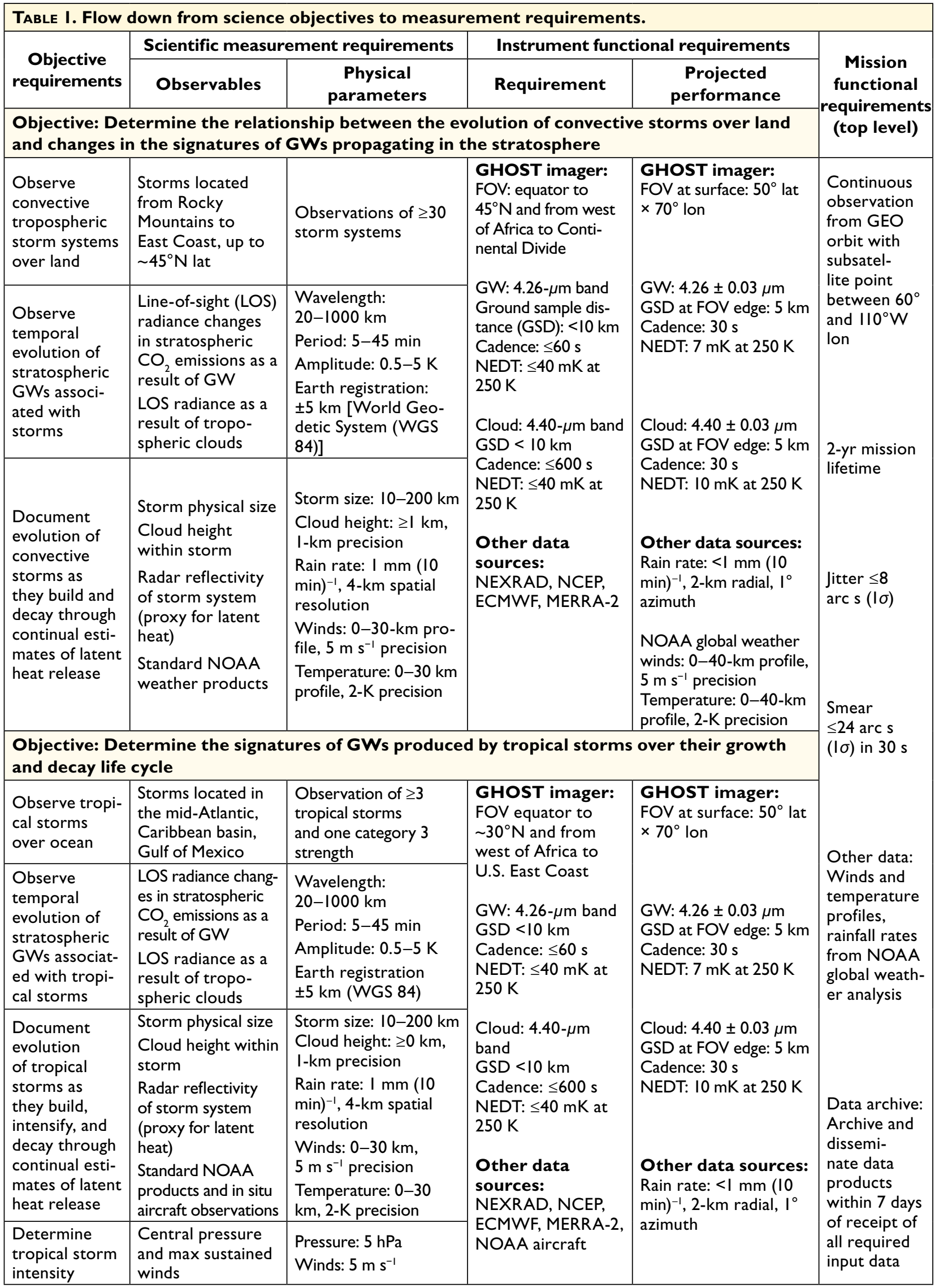


systems are provided by NEXRAD sites in the CONUS (Leone et al. 1989) and pan-Caribbean radar network (Trabal et al. 2013). NEXRAD stations have a maximum range of $230 \mathrm{~km}$ and acquire conventional reflectivity observations and Doppler measurements within storms. NEXRAD also provides some offshore coverage, the most significant being along the Atlantic and Gulf coasts. NEXRAD products are made publicly available through the National Centers for Environmental Prediction (NCEP).

WINDS AND TEMPERATURES. Winds and temperatures are provided by global analysis products [NCEP Global Forecast System (GFS); European Centre for MediumRange Weather Forecasts (ECMWF); Modern-Era Retrospective Analysis for Research and Applications, version 2 (MERRA-2)] and by National Oceanic and Atmospheric Administration (NOAA) aircraft measurements (Doppler radar and dropsondes). The GFS data are provided on a $0.25^{\circ}$ latitude-longitude grid four times daily with an accuracy in the stratosphere of $\sim 3 \mathrm{~m} \mathrm{~s}^{-1}$ for winds and $\sim 2 \mathrm{~K}$ for temperature (Friedrich et al. 2017). Over the CONUS, radiosonde data provide accuracies of $2.5 \mathrm{~m} \mathrm{~s}^{-1}$ for winds and $1 \mathrm{~K}$ for temperature (Ingleby 2016), and over water dropsondes provide similar accuracies.

Models. The WRF Model is a numerical weather prediction and atmospheric simulation tool designed for both research and operational applications (Skamarock et al. 2008). WRF simulations cover a wide range of applications across scales from meters to thousands of kilometers for real data or idealized conditions. WRF offers a variety of physics scheme choices and two dynamical solvers: the Advanced Research version of WRF (WRF-ARW) and the Nonhydrostatic Mesoscale Model (WRF-NMM). A version of WRF-NMM for hurricane forecasting [Hurricane WRF Model (HWRF)] became operational in 2007.

\section{OBSERVATIONAL REQUIREMENTS AND} MISSION PROFILE. Sensor performance requirements. The GHOST instrument performance, as derived from the scientific measurement requirements flow down, is summarized in Table 1. Relevant features of GWs to be measured are amplitude, horizontal wavelength, propagation direction, and frequency. Wavelength and amplitude are derived from individual images, while frequency is derived from image sequences. Figure 4 shows the simulation of waves generated by a very large convective cell ("hot tower") having a total energy release of $1.7 \times 10^{16} \mathrm{~J}$ over $30 \mathrm{~min}$.

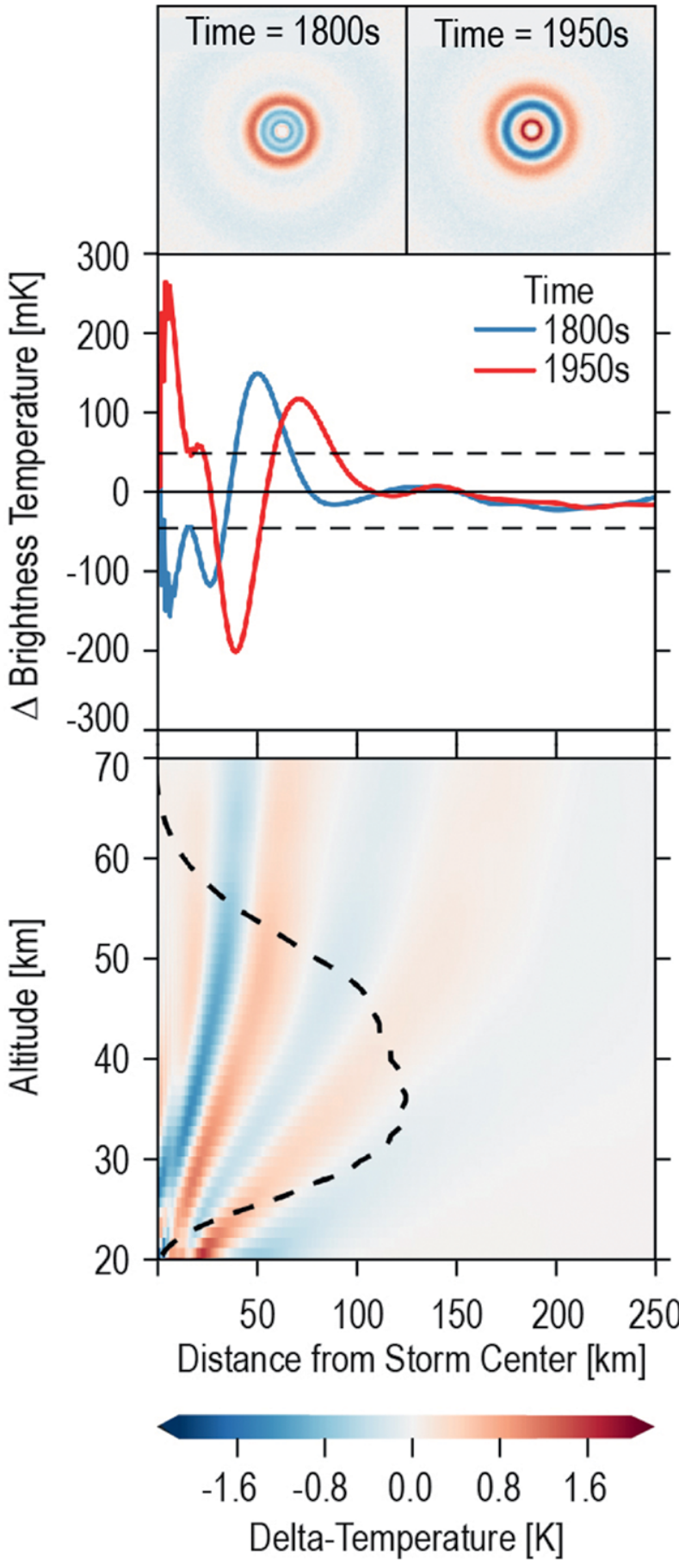

FIG. 4. Simulation of idealized convective GW. (top) Two-dimensional visualizations of the wave. (middle) The GHOST BT sensitivity requirement (dashed lines). (bottom) The 4.3- $\mu \mathrm{m}$ temperature weighting function illustrating vertical coverage.

The model uses a compressible, time-dependent nonlinear code with axisymmetric cylindrical geometry (Walterscheid et al. 2001). The bottom panel shows the vertical temperature disturbance $30 \mathrm{~min}$ after onset with the GHOST temperature kernel overlaid. 
This kernel, which specifies the altitude profile of the relative contribution to the signal seen by the sensor, is convolved with the vertical wave structure to derive the horizontal temperature response shown by the blue line in the middle panel; also shown in red is a wave $150 \mathrm{~s}$ later. Horizontal dashed lines in the middle panel denote GHOST's sensitivity requirement. Radiometric modeling indicates that the actual GHOST sensitivity will exceed the requirement by more than a factor of 5 . The top panels show twodimensional visualizations of the wave, in which the shortest resolved horizontal wavelengths are $\sim 20 \mathrm{~km}$.

Spectral band selection. We are driven to a two-band solution by the science requirement to image GWs at stratospheric altitudes without being sensitive to radiation from clouds at the tropopause $(15 \mathrm{~km}$ and below) and to observe high clouds near the tropopause but not to see the Earth's surface. The strong $\mathrm{CO}_{2}$ band at $4.3 \mu \mathrm{m}$ is preferred to the weak Meinel airglow bands at $1.6 \mu \mathrm{m}$ because the latter are blinded during the daytime and suffer interference from the moon and lights at night. We also dismissed the $\sim 15-\mu \mathrm{m} \mathrm{CO}$ band because of the unavailability of high-heritage arrays with appropriate sensitivity and operability and the increased sensor size needed to meet our spatial resolution requirement. The $4.3-\mu \mathrm{m}$ band is affected by non-local thermodynamic equilibrium (non LTE) effects during the daytime (solar excitation of $\mathrm{CO}_{2}$ molecules); however, this does not

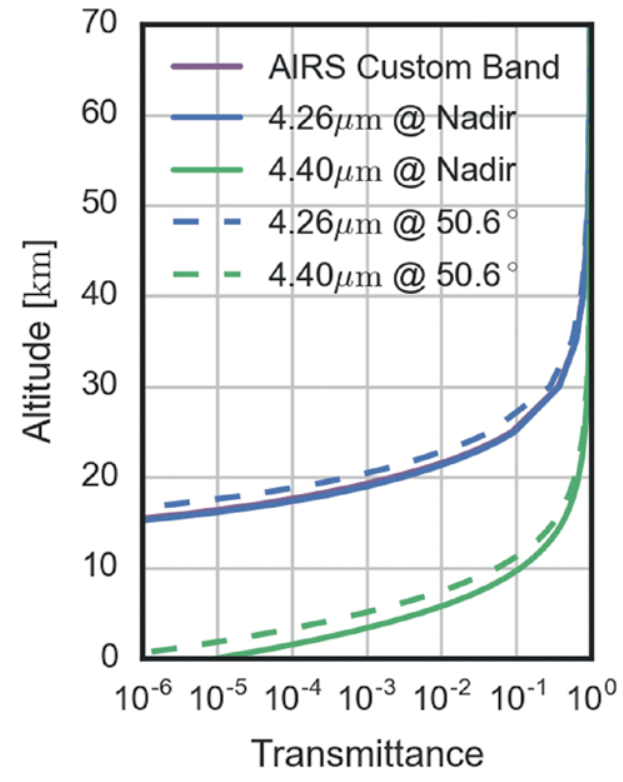

cause problems with the GW data analysis because the non-LTE signals are effectively removed by the application of common detrending methods.

A detailed trade study was conducted to define appropriate filters, combining the community-standard Line-by-Line Radiative Transfer Model (LBLRTM; Clough et al. 2005) high-spectral-resolution atmospheric radiative transfer model with standard filter designs to compute altitude weighting functions for a range of center wavelengths and bandpasses. A band near $4.26 \mu \mathrm{m}$ samples the stratosphere at $25-55-\mathrm{km}$ altitudes with the temperature kernel shown in Fig. 5. Note the similarity here to the AIRS synthetic band, which is also shown for comparison. A band near $4.40 \mu \mathrm{m}$ samples at a low-enough altitude to detect high-altitude clouds that indicate storm strength. The difference in the weighting functions between the two nadir angles evident in Fig. 5 is due to the concomitant change in atmospheric pathlength between the sensor and observation altitudes at the two nadir angle settings.

Storm observation requirements. Table 1 summarizes the data sources required to meet the science requirements. Accumulating meaningful statistics for landbased convective storms requires the observation of at least 30 such storms over CONUS. Named TCs averaged 4.2 per annum in the Caribbean basin for the period 1900-2008 (Klotzbach 2011). More recent statistics for the period 1990-2014 bear out this trend, indicating that in any one year one might expect approximately four storms of sufficient strength to pass within range of one or more stations comprising the CONUS and panCaribbean radar networks (https://stormcarib.com/), increasing to 7.2 per annum when including U.S. coastal radar sites. Thus, we would expect to meet the requirement of observing at least three TCs with supporting radar observations using just these sites during a 2-yr period.

Mission profile. The GHOST host is a GEO satellite stationed between $60^{\circ}$ and $110^{\circ} \mathrm{W}$ longitude. The need for a GEO host is driven by the requirement to collect 

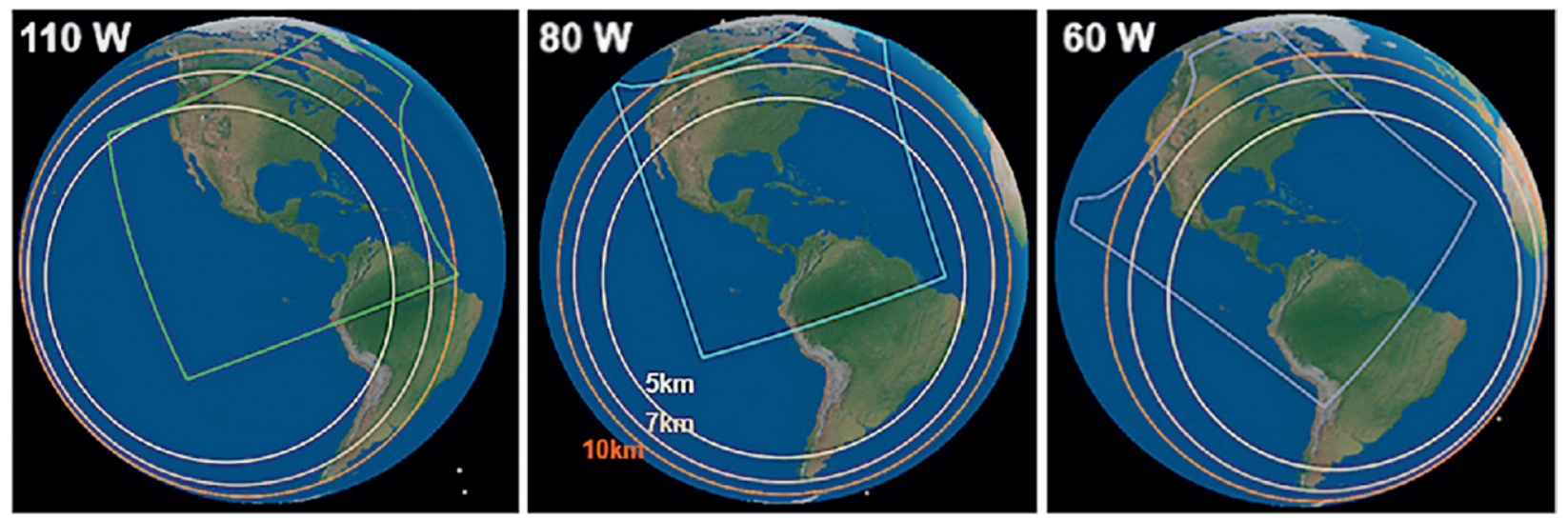

FIG. 6. GHOST ground footprints. Area within which pixel footprints are less than 5,7 , and $10 \mathrm{~km}$ (circles). Required areas of interest are imaged from all satellite locations between $60^{\circ}$ and $110^{\circ} \mathrm{W}$.

continuous images day and night. An LEO-based approach requires an impractically large number of satellites to collect images at the required minutes-long cadence and hours-long dwell over a $500-\mathrm{km}$ radius. The host longitude is driven by the requirement to observe the Atlantic hurricane belt and severe storms in the U.S. Midwest with 5-km-or-better pixel sampling to meet all elements of the science plan. There is considerable flexibility in host longitude. Figure 6 shows candidate GHOST sensor footprints for selected spacecraft longitudes and illustrates that the principal areas of interest are accessible from a broad range of longitudes. The GHOST mechanical interface would be preset before launch for the intended field of view (FOV). Data are downlinked continuously from the sensor at $6.5 \mathrm{Mbps}$. Preprogrammed calibration sequences require no special accommodation in the downlink and do not interfere with regular data collection. As a result GHOST operates autonomously, requiring no operator intervention to collect the data needed to meet its science goals.

CONCLUDING REMARKS. Despite recent advances (e.g., Kaplan et al. 2015), the accurate forecasting of TC intensity change stands as one of the foremost challenges in meteorology (Doyle et al. 2017). The concept described in this paper is intended to address this deficiency by undertaking continuous, high-spatiotemporal observation of GWs generated by TCs, and also convective severe storms, throughout their life cycles. To achieve this objective, GHOST would conduct persistent surveillance of the Atlantic hurricane and CONUS severe storm belts. A recent publication concluded (Miller et al. 2015, p. E6734), "A future geostationary-based system-one coupling nightglow-sensitive visible/ near-infrared with the middlewave infrared bands used for stratospheric wave detection-would enable high temporal sampling and a true quantum leap in our ability to characterize the $3 \mathrm{D}$, transient behavior of upper atmospheric gravity waves."

GHOST would complement upcoming microwave TC measurements (e.g., Zavodsky et al. 2017) and augment the high-cadence visible and near-infrared imaging capabilities currently afforded by GOES-16 and Himawari with analogous midwave infrared imagery. GHOST would reduce the uncertainty in our knowledge of the link between stratospheric GWs and the storms that give rise to them. GHOST data offer the possibility that future operational GEO weather satellites could host sensors with similar functionality for improvement of storm development prediction skill.

\section{REFERENCES}

Alexander, M. J., and J. R. Holton, 2004: On the spectrum of vertically propagating gravity waves generated by a transient heat source. Atmos. Chem. Phys., 4, 923-932, https://doi.org/10.5194/acp-4-923-2004.

— S. D. Eckermann, D. Broutman, and J. Ma, 2009: Momentum flux estimates for South Georgia Island mountain waves in the stratosphere observed via satellite. Geophys. Res. Lett., 36, L12816, https:/doi .org/10.1029/2009GL038587.

— , and Coauthors, 2010: Recent developments in gravity-wave effects in climate models and the global distribution of gravity-wave momentum flux from observations and models. Quart. J. Roy. Meteor. Soc., 136, 1103-1124, https://doi.org/10.1002/qj.637.

Beres, J. H., M. J. Alexander, and J. R. Holton, 2004: A method of specifying the gravity wave spectrum above convection based on latent heating properties and background wind. J. Atmos. Sci., 61, 324-337, 
https://doi.org/10.1175/1520-0469(2004)061<0324:AM OSTG>2.0.CO;2.

Chow, K. C., K. L. Chan, and A. K. H. Lau, 2002: Generation of moving spiral bands in tropical cyclones. J. Atmos. Sci., 59, 2930-2950, https://doi.org/10.1175/1520 -0469(2002)059<2930:GOMSBI>2.0.CO;2.

Clough, S. A., M. W. Shephard, E. J. Mlawer, J. S. Delamere, M. J. Iacono, K. Cady-Pereira, S. Boukabara, and R. D. Brown, 2005: Atmospheric radiative transfer modeling: A summary of the AER codes. J. Quant. Spectrosc. Radiat. Transfer, 91, 233-244, https://doi.org/10.1016/j.jqsrt.2004.05.058.

de Groot-Hedlin, C. D., M. A. H. Hedlin, L. Hoffmann, M. J. Alexander, and C. C. Stephan, 2017: Relationships between gravity waves observed at Earth's surface and in the stratosphere over the central and eastern United States. J. Geophys. Res. Atmos., 122, 11482-11 498, https://doi.org/10.1002/2017JD027159.

DeMaria, M., C. R. Sampson, J. A. Knaff, and K. D. Musgrave, 2014: Is tropical cyclone intensity guidance improving? Bull. Amer. Meteor. Soc., 95, 387-398, https://doi.org/10.1175/BAMS-D-12-00240.1.

Doyle, J. D., and Coauthors, 2017: A view of tropical cyclones from above: The Tropical Cyclone Intensity experiment. Bull. Amer. Meteor. Soc., 98, 2113-2134, https://doi.org/10.1175/BAMS-D-16-0055.1.

Emanuel, K., 2017: Will global warming make hurricane forecasting more difficult? Bull. Amer. Meteor. Soc., 98, 495-501, https://doi.org/10.1175/BAMS -D-16-0134.1.

Friedrich, L. S., A. J. McDonald, G. E. Bodeker, K. E. Cooper, J. Lewis, and A. J. Paterson, 2017: A comparison of Loon balloon observations and stratospheric reanalysis products. Atmos. Chem. Phys., 17, 855-866, https://doi.org/10.5194/acp-17-855-2017.

Fritts, D. C., and M. J. Alexander, 2003: Gravity wave dynamics and effects in the middle atmosphere. Rev. Geophys., 41, 1003, https://doi .org/10.1029/2001RG000106.

Grimsdell, A. W., M. J. Alexander, P. T. May, and L. Hoffmann, 2010: Model study of waves generated by convection with direct validation via satellite. J. Atmos. Sci., 67, 1617-1631, https://doi .org/10.1175/2009JAS3197.1.

Guimond, S. R., G. M. Heymsfield, and F. J. Turk, 2010: Multiscale observations of Hurricane Dennis (2005): The effects of hot towers on rapid intensification. J. Atmos. Sci., 67, 633-654, https://doi .org/10.1175/2009JAS3119.1.

Hecht, J. H., and Coauthors, 2009: Imaging of atmospheric gravity waves in the stratosphere and upper mesosphere using satellite and ground-based observations over Australia during the TWPICE campaign. J. Geophys. Res., 114, D18123, https://doi .org/10.1029/2008JD011259.

Hendricks, E. A., W. H. Schubert, S. R. Fulton, and B. D. McNoldy, 2010: Spontaneous-adjustment emission of inertia-gravity waves by unsteady vortical motion in the hurricane core. Quart. J. Roy. Meteor. Soc., 136, 537-548, https://doi.org/10.1002/qj.547.

Hoffmann, L., and M. J. Alexander, 2010: Occurrence frequency of convective gravity waves during the North American thunderstorm season. J. Geophys. Res., 115, D20111, https://doi.org/10.1029/2010JD014401.

—, X. Xue, and M. J. Alexander, 2013: A global view of stratospheric gravity wave hotspots located with Atmospheric Infrared Sounder observations. J. Geophys. Res. Atmos., 118, 416-434, https://doi .org/10.1029/2012JD018658.

,-- , C. Clerbaux, A. W. Grimsdell, C. I. Meyer, T. Rößler, and B. Tournier, 2014: Intercomparison of stratospheric gravity wave observations with AIRS and IASI. Atmos. Meas. Tech., 7, 4517-4537, https:// doi.org/10.5194/amt-7-4517-2014.

— X. Wu, and M. J. Alexander, 2018: Satellite observations of stratospheric gravity waves associated with the intensification of tropical cyclones. Geophys. Res. Lett., 45, 1692-1700, https://doi.org/10.1002/2017GL076123.

Holton, J. R., 1972: Waves in the equatorial stratosphere from tropospheric heat sources. J. Atmos. Sci., 29, 368-375, https://doi.org/10.1175/1520 -0469(1972)029<0368:WITESG>2.0.CO;2.

- J. H. Beres, and X. Zhou, 2002: On the vertical scale of gravity waves excited by localized thermal forcing. J. Atmos. Sci., 59, 2019-2023, https://doi .org/10.1175/1520-0469(2002)059<2019:OTVSOG $>2.0 . \mathrm{CO} ; 2$.

Houze, R. A., Jr., and Coauthors, 2006: The hurricane rainband and intensity change experiment: Observations and modeling of Hurricanes Katrina, Ophelia, and Rita. Bull. Amer. Meteor. Soc., 87, 1503-1522, https://doi.org/10.1175/BAMS-87-11-1503.

Ingleby, B., 2016: On the accuracy of different radiosonde types. WMO Instruments and Observing Methods Rep. 125, O4(8), 10 pp., www.wmo.int/pages/prog /www/IMOP/publications/IOM-125_TECO_2016 /Session_4/O4(8)_Ingleby_RadiosondeTypes.pdf.

Jensen, M. P., and Coauthors, 2016: The Midlatitude Continental Convective Clouds Experiment (MC3E). Bull. Amer. Meteor. Soc., 97, 1667-1698, https://doi .org/10.1175/BAMS-D-14-00228.1.

Kaplan, J., and Coauthors, 2015: Evaluating environmental impacts on tropical cyclone rapid intensification predictability utilizing statistical models. Wea. Forecasting, 30, 1374-1396, https://doi.org/10.1175 /WAF-D-15-0032.1. 
Kelley, O. A., J. Stout, and J. B. Halverson, 2004: Tall precipitation cells in tropical cyclones eyewalls are associated with tropical cyclone intensification. Geophys. Res. Lett., 31, L24112, https://doi .org/10.1029/2004GL021616.

Klotzbach, P. J., 2011: The influence of El Niño-Southern Oscillation and the Atlantic Multidecadal Oscillation on Caribbean tropical cyclone activity. J. Climate, 24, 721-731, https://doi.org/10.1175 /2010JCLI3705.1.

Knapp, K. R., M. C. Kruk, D. H. Levinson, H. J. Diamond, and C. J. Neumann, 2010: The International Best Track Archive for Climate Stewardship (IBTrACS): Unifying tropical cyclone data. Bull. Amer. Meteor. Soc., 91, 363-376, https://doi .org/10.1175/2009BAMS2755.1.

Kuester, M. A., M. J. Alexander, and E. A. Ray, 2008: A model study of gravity waves over Hurricane Humberto (2001). J. Atmos. Sci., 65, 3231-3246, https://doi .org/10.1175/2008JAS2372.1.

Landsea, C. W., and J. L. Franklin, 2013: Atlantic hurricane database uncertainty and presentation of a new database format. Mon. Wea. Rev., 141, 3576-3592, https://doi.org/10.1175/MWR-D-12-00254.1.

Lee, C.-Y., M. K. Tippett, A. H. Sobel, and S. J. Camargo, 2016: Rapid intensification and the bimodal distribution of tropical cyclone intensity. Nat. Commun., 7, 10625, https://doi.org/10.1038/ncomms10625.

Leone, D. A., R. M. Endlich, J. Petričeks, R. T. H. Collis, and J. R. Porter, 1989: Meteorological considerations used in planning the NEXRAD network. Bull. Amer. Meteor. Soc., 70, 4-13, https://doi.org/10.1175/1520 -0477(1989)070<0004:MCUIPT>2.0.CO;2.

Levi, A., and A. Agheli, 2011: CHIRP technology demonstration project. Proc. AIAA SPACE 2011 Conf. and Exposition, Long Beach, CA, AIAA, AIAA 2011-7333, https://doi.org/10.2514/6.2011-7333.

Miller, S. D., W. C. Straka III, J. Yue, S. M. Smith, M. J. Alexander, L. Hoffmann, M. Setvák, and P. T. Partain, 2015: Upper atmospheric gravity wave details revealed in nightglow satellite imagery. Proc. Natl. Acad. Sci. USA, 112, E6728-E6735, https://doi.org/10.1073 /pnas.1508084112.

National Science Board, 2007: Hurricane warning: The critical need for a national hurricane research initiative. National Science Foundation Rep. NSB06-115, 36 pp., https://nsf.gov/nsb/publications/2007 /hurricane/initiative.pdf.

Nicholls, M. E., R. A. Pielke, and W. R. Cotton, 1991: Thermally forced gravity waves in an atmosphere at rest. J. Atmos. Sci., 48, 1869-1884, https://doi .org/10.1175/1520-0469(1991)048<1869:TFGWIA $>2.0 . \mathrm{CO} ; 2$.
Nolan, D. S., 2011: Evaluating environmental favorableness for tropical cyclone development with the method of point-downscaling. J. Adv. Model. Earth Syst., 3, M08001, https://doi.org/10.1029/2011MS000063.

— , and J. A. Zhang, 2017: Spiral gravity waves radiating from tropical cyclones. Geophys. Res. Lett., $\mathbf{4 4}$ 3924-3931, https://doi.org/10.1002/2017GL073572.

OFCM, 2006: Doppler radar meteorological observations. Part C: WSR-88D products and algorithms. Federal Meteorological Handbook 11, OFCM Tech. Rep. FCM-393 H11C-2006, 390 pp., http://wlnpp.org /wxlgyx.org/TOPICS/WX/FMH-11 2.pdf.

Pfister, L., S. Scott, M. Loewenstein, S. Bowen, and M. Legg, 1993: Mesoscale disturbances in the tropical stratosphere excited by convection: Observations and effects on the stratospheric momentum budget. J. Atmos. Sci., 50, 1058-1075, https://doi. org/10.1175/1520-0469(1993)050<1058:MDITTS> 2.0.CO;2.

Rappaport, E. N., and Coauthors, 2009: Advances and challenges at the National Hurricane Center. Bull. Amer. Meteor. Soc., 24, 395-419, https://doi.org /10.1175/2008WAF2222128.1.

Rauscher, B. J., and Coauthors, 2014: New and better detectors for the JWST Near-Infrared Spectrograph. Publ. Astron. Soc. Pac., 126, 739-749, https://doi.org /10.1086/677681.

Rogers, R. F., P. D. Reasor, and S. Lorsolo, 2013: Airborne Doppler observations of the inner-core structural differences between intensifying and steady-state tropical cyclones. Mon. Wea. Rev., 141, 2970-2991, https://doi.org/10.1175/MWR-D-12-00357.1.

_ - and Coauthors, 2017: Re-writing the tropical record books: The extraordinary intensification of Hurricane Patricia (2015). Bull. Amer. Meteor. Soc., 98, 2091-2112, https://doi.org/10.1175/BAMS -D-16-0039.1.

Schecter, D. A., 2008: The spontaneous imbalance of an atmospheric vortex at high Rossby number. J. Atmos. Sci., 65, 2498-2521, https://doi .org/10.1175/2007JAS2490.1.

Schueler, C. F., 2012: FD-CHIRP: Hosted payload system engineering lessons. Remote Sensing System Engineering IV, P. E. Ardanuy and J. J. Puschell, Eds., International Society for Optics and Photonics (SPIE Proceedings, Vol. 8516), 851607, https://doi .org/10.1117/12.942539.

Shige, S., Y. N. Takayabu, W.-K. Tao, and D. E. Johnson, 2004: Spectral retrieval of latent heating profiles from TRMM PR Data. Part I: Development of a modelbased algorithm. J. Appl. Meteor., 43, 1095-1113, https://doi.org/10.1175/1520-0450(2004)043<1095:SR OLHP $>2.0 . C O ; 2$. 
Skamarock, W. C., and Coauthors, 2008: A description of the Advanced Research WRF version 3. NCAR Tech. Note NCAR/TN-475+STR, 113 pp., https://doi. org/10.5065/D68S4MVH.

Stephan, C., and M. J. Alexander, 2014: Summer season squall-line simulations: Sensitivity of gravity waves to physics parameterization and implications for their parameterization in global climate models. $J$. Atmos. Sci., 71, 3376-3391, https://doi.org/10.1175 /JAS-D-13-0380.1.

— , and — , 2015: Realistic simulations of atmospheric gravity waves over the continental U.S. using precipitation radar data. J. Adv. Model. Earth Syst., 7, 823-835, https://doi.org/10.1002/2014MS000396.

,$- \ldots$, M. Hedlin, C. D. de Groot-Hedlin, and L. Hoffmann, 2016: A case study on the far-field properties of propagating tropospheric gravity waves. Mon. Wea. Rev., 144, 2947-2961, https://doi .org/10.1175/MWR-D-16-0054.1.

Trabal, J. M., J. G. Colom-Ustariz, S. L. Cruz-Pol, G. A. Pablos-Vega, and D. J. McLaughlin, 2013: Remote sensing of weather hazards using a low-cost and minimal infrastructure off-the-grid weather radar network. IEEE Trans. Geosci. Remote Sens., 51, 25412555, https://doi.org/10.1109/TGRS.2012.2214227.
Walterscheid, R. L., and A. B. Christensen, 2016: Lowlatitude gravity wave variances in the mesosphere and lower thermosphere derived from SABER temperature observation and compared with model simulation of waves generated by deep tropical convection. J. Geophys. Res. Atmos., 121, 11900-11912, https://doi.org/10.1002/2016JD024843.

—, G. Schubert, and D. G. Brinkman, 2001: Smallscale gravity waves in the upper mesosphere and lower thermosphere generated by deep tropical convection. J. Geophys. Res., 106, 31 825-31 832, https:// doi.org/10.1029/2000JD000131.

Willoughby, H. E., J. A. Clos, and M. G. Shoreibah, 1982: Concentric eye walls, secondary wind maxima, and the evolution of the hurricane vortex. J. Atmos. Sci., 39, 395-411, https://doi.org/10.1175/1520-0469 (1982)039<0395:CEWSWM>2.0.CO;2.

Zavodsky, B., J. Dunion, W. Blackwell, S. Braun, C. Velden, M. Brennan, and R. Adler, 2017: First Time-Resolved Observations of Precipitation Structure and Storm Intensity with a Constellation of SmallSats (TROPICS) mission applications workshop summary report. NASA Rep. NASA/CP-2017-219705, 40 pp., https://doi.org/2060/20170010652.

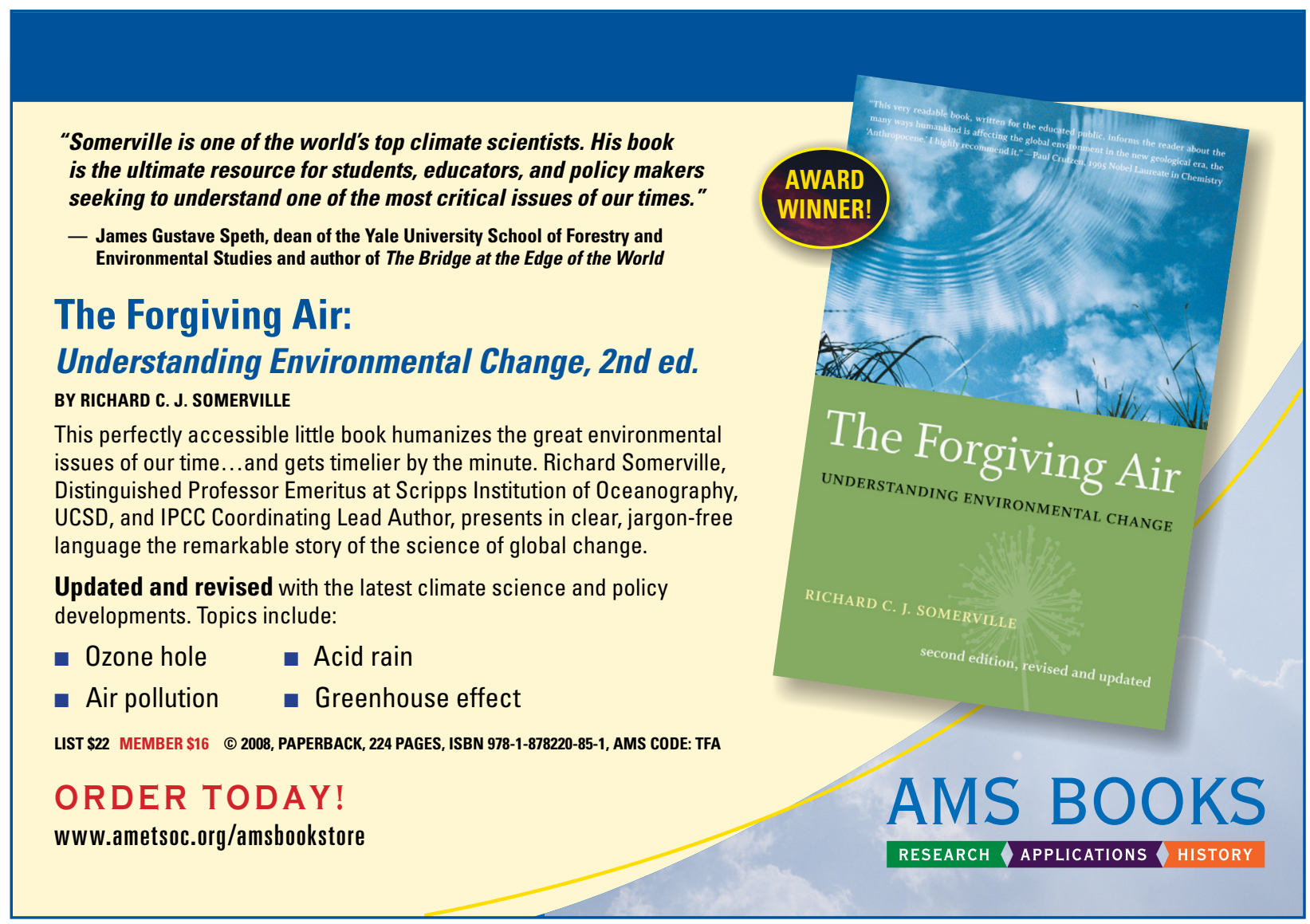

